\title{
PREDICTIVE VALUE OF PLASMA FIBRINOGEN LEVELS FOR OUTCOME OF ANEURYSMAL SUBARACHNOID HAEMORRHAGE DURING THE FIRST WEEK OF ILLNESS
}

\author{
Bartosz Sokół', Norbert Wąsik', Catherine Olczyk', Barbara Więckowska², \\ Robert Juszkat ${ }^{1,3}$, Roman Jankowski \\ 'Department and Clinic of Neurosurgery and Neurotraumatology, Poznan University \\ of Medical Sciences, Poznan, Poland \\ ${ }^{2}$ Department of Computer Science and Statistics, Poznan University of Medical Sciences, \\ Poznan, Poland \\ ${ }^{3}$ Department of General and Interventional Radiology, Poznan University of Medical Sciences, \\ Poznan, Poland
}

\begin{abstract}
Objectives: Aneurysmal subarachnoid haemorrhage (SAH) is an acute cerebrovascular event characterised by the rupture of an aneurysm within the subarachnoid space. Secondary injuries increase both mortality and morbidity in patients who survive the primary haemorrhage. Inflammation and coagulation play critical roles in the pathophysiology of SAH. Fibrinogen is involved in both, yet despite wide availability, its prognostic value in aneurysmal SAH is not clear.

Material and methods: A prospectively collected database of 97 aneurysmal SAH patients was reviewed for plasma fibrinogen level results. All patients admitted within 24 hours of aneurysm rupture and treated endovascularly within 48 hours were included. The outcome was assessed at three months according to the Glasgow Outcome Scale (GOS). Correlation with the outcome and analysis for patients' death and unfavourable outcome were performed.

Results: Fibrinogen level on day 2 significantly correlates with GOS at 3 months. The analysis for mortality revealed that high levels of fibrinogen on days 1,2 and 3-4 were significant, but not independent predictors for mortality. Univariate analysis for unfavourable outcome indicated no significant prognostic value of fibrinogen levels. Statistically significant elevation of fibrinogen level was found on day 2 in patients with an intraventricular haematoma $(p<0.01)$. We also noted that fibrinogen level was elevated in patients with a Glasgow Coma Scale score less than $13(p=0.013)$.

Conclusions: Fibrinogen level might serve as an accessory prognostic tool for patients' death. Fibrinogen level was significantly elevated in patients with intraventricular haematoma and in patients with a poor clinical condition on admission.
\end{abstract}

Key words: subarachnoid haemorrhage, early brain injury, outcome.

\author{
ORIGINAL PAPER \\ Phlebological Review 2018; 26, 2: 36-43 \\ D0l: https://doi.org/10.5114/pr.2018.81011
}

Submitted: 27.05 .2018

Accepted: 8.08.2018

\section{ADDRESS FOR CORRESPONDENCE \\ Bartosz Sokół \\ Department and Clinic of Neurosurgery \\ and Neurotraumatology \\ Poznan University of Medical Sciences \\ 49 Przybyszewskiego St. \\ 60-355 Poznan, Poland \\ e-mail: bartosz.sokol@ump.edu.pl}

\section{INTRODUCTION}

The annual incidence of cerebral aneurysm rupture is 1 in 10,000 for the general population. This devastating condition kills or severely disables $70 \%$ of victims [1-3]. Those who survive aneurysmal haemorrhage often suffer delayed ischaemic neurological deficits (DINDs). Unfortunately, despite the significant consequences of DINDs, prompt diagnosis can be elusive, and may result in delay of administering effective treatment and compromise patient outcome. Despite the improvement of treatment options, the outlook remains serious. Therefore, all available data should be used to characterise adverse factors and indicate pathophysiological mechanisms leading to deterioration [4]. Currently, the most widely used markers of aneurysmal subarachnoid haemorrhage (SAH) prognosis are age, neurological state, volume of subarachnoid blood measured by computed tomography (CT) at admission, pre-existing hypertension, and complications such as aneurysmal rebleeding or angiographic vasospasm $[5,6]$. Several scales, including the Glasgow Outcome Scale (GOS) [7], Hunt and Hess scale $(\mathrm{HH})[8]$, World Federation of Neurological Societies scale (WFNS) [9], and Fisher scale [10], are known to be associated with SAH clinical outcomes [11]. It has been suggested that factors other than SAH 
alone may play a role in the development of vasospasm. The possibility of exploring genetic links to vasospasm was raised by Rabb et al. in 1994 [12]. Early brain injury $(\mathrm{EBI})$, defined as damage sustained within 72 hours of the ictus, has been attributed to an interplay between alterations in cerebral blood flow (CBF) autoregulation, disrupted cerebral metabolism, altered permeability of the blood-brain barrier (BBB), as well as inflammatory cytokines, leukocytes and pro-thrombotic pathways [13, 14]. Results from CONSCIOUS trials have suggested that early brain injury immediately follows SAH and precedes the onset of delayed vasospasm [15-17]. EBI is a result of increased intracranial pressure and decreased $\mathrm{CBF}$, causing cerebral ischaemia. These early events are followed by neuroinflammation, BBB breakdown, and neuronal apoptosis $[18,19]$. After SAH, brain injuries from the initial haemorrhage occurring within 72 hours and cerebral vasospasm developing 3-7 days after rupture are the most important causes of mortality and morbidity [20]. Numerous studies suggest that inflammation and coagulation play key roles in the pathophysiology of SAH and contribute to the functional and cognitive outcomes [21-23]. Identifying a plasma biomarker with early prognostic value for SAH outcome is attracting increased attention [24, 25] and could aid in identifying high-risk patients, guide treatment and improve outcome. Unfortunately, clinically reliable blood biomarkers are still not available. In this study, changes in plasma fibrinogen levels were measured in patients diagnosed with $\mathrm{SAH}$ in an attempt to correlate levels of this biomarker with clinical outcomes.

\section{MATERIAL AND METHODS Patient population}

This prospective observational study was conducted at a single academic tertiary care centre over a one-year period. All patients were admitted within 24 hours of confirmed aneurysmal SAH. The diagnosis was based on computed tomography and catheter angiography. None of the enrolled patients had a history of any chronic neurological disorder or chronic inflammatory disease; there was no history of surgical procedures or nosocomial infection within four weeks of SAH onset. All patients underwent cerebral angiography with arterial catheterisation or multislice CT angiography within 48 hours of onset.

\section{Ethics and consent}

This prospective observational study was conducted in accordance with the Declaration of Helsinki. The Poznan University of Medical Sciences Bioethics Committee approved the study protocol, consenting protocol and consent forms. Patients were assessed by two specialists (a neurosurgeon and an anaesthesiologist) as to their ability to give informed consent for inclusion in the study, and permission to use blinded medical data for analysis and publication.

\section{Population: inclusion and exclusion criteria}

Ninety-seven patients with SAH (confirmed by non-contrast $\mathrm{CT}$ ) were referred to our department during the study recruitment period from October 2015 to October 2016. Data were collected prospectively and analysed retrospectively. All patients had an aneurysmal SAH treated endovascularly within 48 hours of rupture. Exclusion criteria were: 1) history of central nervous system (CNS) disease, 2) active CNS infection, 3 ) active systemic disease (diabetes mellitus, rheumatoid arthritis, malignancy, cirrhosis, renal failure), 4) age under 18, 5) pregnancy.

\section{Management, definitions, endpoints}

On admission the clinical status was assessed using the GCS and specific SAH-grading scales (HH [26], WFNS [27]). Patients received a continuous infusion of nimodipine for at least ten days, hypotension was avoided using vasopressors and euvolaemia was maintained. Induced hypertension (20-30\% above baseline levels) was used to treat patients diagnosed with delayed cerebral ischaemia (DCI), based on the appearance of a new focal deficit, or a drop of at least two points on the GCS lasting at least two hours after the exclusion of systematic causes. The primary end point was the treatment outcome assessed at three months using GOS [28]. Patients were divided into two groups according to the GOS. The good outcome group consisted of those with no disability, moderate disability or severe disability (GOS grades 5, 4 and 3); the poor outcome group consisted of those with a persistent vegetative state or death (GOS grades 2 and 1). DCIrelated infarction was defined as a new cerebral infarction identified on a head CT scan within six weeks of rupture and not present on the immediate post-treatment scan (as proposed by Vergouwen et al. [17]).

\section{Fibrinogen assay}

During hospitalisation, decisions regarding type and timing of laboratory tests (including fibrinogen levels) were left solely to the judgement of the physician. Consequently, the number of subjects available for analysis at each time point varied. The fibrinogen level was assessed using the automatic analyser ACL TOP 500 (Instrumentation Laboratory, Italy).

\section{Statistical analysis}

Statistica 12 software (Stat Soft Inc., Tulsa, OK, USA) was used to perform all analyses. The Shapiro-Wilk test was used to test the normality of the data distribu- 
Table 1. Patient characteristics

\begin{tabular}{lc}
\hline Variables & Descriptive statistics \\
\cline { 2 - 2 } & $n=97(\%)$ \\
\hline Male & $47(48)$ \\
\hline Age (years) & $56.0 \pm 14.2$ \\
\hline Aneurysm location & $22(22.7)$ \\
\hline Middle cerebral artery & $27(27.8)$ \\
\hline Anterior communicating artery & $22(22.7)$ \\
\hline Internal carotid artery & $7(7.2)$ \\
\hline Anterior cerebral artery & $10(10.3)$ \\
\hline Basilar artery & $1(1)$ \\
\hline Posterior cerebral artery & $3(3.1)$ \\
\hline Vertebral artery & $5(5.2)$ \\
\hline Posterior inferior cerebellar artery & $5.5 \pm 2.8$ \\
\hline Aneurysmal size (mm) & $4(4 ; 4)$ \\
\hline Fisher CT scale & $3(2 ; 4)$ \\
\hline Modified Fisher CT scale & $4(2 ; 5)$ \\
\hline HH grade on admission & $4(2 ; 5)$ \\
\hline WFNS grade on admission & $7(4 ; 13)$ \\
\hline GCS on admission & $19(19.6)$ \\
\hline Treatment outcome according to G0S at 3 months & $10(10.3)$ \\
\hline 5 (no/low disability) & $25(25.8)$ \\
\hline 4 (moderate disability) & $13(13.4)$ \\
\hline 3 (severe disability) & $30(30.9)$ \\
\hline 2 (persistent vegetative state) & \\
\hline 1 (death) & \\
\hline
\end{tabular}

Values are presented as: 1) mean \pm standard deviation for numerical data, 2) median (lower quartile, upper quartile) for ordinal data, 3) count (percentage) for categorical/ ordinal data. WFNS - World Federation of Neurosurgical Societies scale; $\mathrm{HH}$ - Hunt and Hess scale; GCS - Glasgow Coma Scale; GOS - Glasgow Outcome Scale. tion. Student's t-test, Cochran-Cox correction, and the Mann-Whitney test were used for pairwise comparisons, i.e. favourable vs. unfavourable outcome, and survivors vs. non-survivors. Spearman's test was used to assess correlation: a correlation coefficient (cc) of $>0.4$ or $<-0.4$ was considered significant. To identify independent prognostic factors for unfavourable outcome and mortality, univariate and multivariate logistic regression analysis adjusted for $\mathrm{HH}$ and age was performed as appropriate.

\section{RESULTS}

Ninety-seven subjects ( $45 \%$ males; mean 56 years) were included in the study based on the availability of fibrinogen assay data. On admission, $57 \%$ of patients were classified as poor grade (HH grades 4 and 5). At three months, $69 \%$ of patients had an unfavourable outcome (GOS scores 1-3), including 31\% who died (Table 1). Pairwise comparison of favourable and unfavourable treatment outcome groups is presented in Table 2. Both age $(p=0.0226)$ and clinical status on admission ( $p<0.0001$ on all three scales) differed significantly between the two groups. The fibrinogen level was unable to differentiate between the favourable and unfavourable groups (Fig. 1). Table 3 and Figure 2 present a pairwise comparison of survivors and non-survivors. Analysis showed that clinical status on admission was significantly different between the groups ( $p \leq 0.0001$ on all three scales), but the age rating did not reach significance $(p=0.0642)$. Significantly higher fibrinogen levels on day $2(p=0.0302)$ and day 3-4 $(p=0.0459)$ were found in non-survivors (Fig. 2). Correlation analysis for this cohort (Table 4) showed the closest correlation with admission status; the coefficient was $-0.679,-0.699$ and -0.630 for the GCS, HH and WFNS scores, respectively. There was a significant association between outcome and

Table 2. Comparison between favourable and unfavourable outcome in subarachnoid haemorrhage patients

\begin{tabular}{|c|c|c|c|c|c|}
\hline \multirow[t]{2}{*}{ Variables } & \multicolumn{2}{|r|}{ Favourable outcome } & \multicolumn{2}{|c|}{ Unfavourable outcome } & \multirow[t]{2}{*}{$p$-value } \\
\hline & $n$ & mean $\pm \mathrm{SD} /$ median $(\mathrm{Q} 1 ; \mathrm{Q} 3)$ & $n$ & mean $\pm \mathrm{SD} /$ median $(\mathrm{Q} 1 ; \mathrm{Q} 3)$ & \\
\hline Age & 29 & $51.0 \pm 14.9$ & 68 & $58.1 \pm 13.4$ & $0.0226^{*}$ \\
\hline $\mathrm{HH}$ on admission & 29 & $2(2 ; 3)$ & 68 & $5(4 ; 5)$ & $<0.0001^{*}$ \\
\hline WFNS on admission & 29 & $1(1 ; 3)$ & 68 & $5(4 ; 5)$ & $<0.0001^{*}$ \\
\hline GCS on admission & 29 & $15(12 ; 15)$ & 68 & $6(3 ; 9)$ & $<0.0001^{*}$ \\
\hline Fibrinogen $(\mathrm{mg} / \mathrm{dl})$, day 0 & 16 & $282.3 \pm 73.5$ & 30 & $306.2 \pm 98.5$ & 0.3993 \\
\hline Fibrinogen $(\mathrm{mg} / \mathrm{dl})$, day 1 & 9 & $274.7 \pm 83.4$ & 29 & $348.1 \pm 130.1$ & 0.1591 \\
\hline Fibrinogen (mg/dl), day 2 & 9 & $391.4 \pm 116.8$ & 20 & $472.5 \pm 141.6$ & 0.1454 \\
\hline Fibrinogen (mg/dl), days 3-4 & 11 & $447.5 \pm 177.0$ & 36 & $603.6 \pm 251.4$ & 0.0875 \\
\hline Fibrinogen (mg/dl), days 5-7 & 6 & $703.8 \pm 243.7$ & 40 & $726.4 \pm 225.4$ & 0.8218 \\
\hline Fibrinogen $(\mathrm{mg} / \mathrm{dl})$, days 9-11 & 6 & $703.3 \pm 231.7$ & 37 & $673.7 \pm 247.7$ & 0.7855 \\
\hline
\end{tabular}

Statistical significance for pairwise comparisons between the groups of death/survivor was tested by Student's t-test, Cochran-Cox correction or the Mann-Whitney test as appropriate. Values are presented as: 1) mean \pm standard deviation for numerical data, 2) median (lower quartile, upper quartile) for ordinal data. "significant p-value. GCS - Glasgow Coma Scale; HH - Hunt and Hess scale; Q - quartile; SD - standard deviation; WFNS - World Federation of Neurosurgical Societies scale 


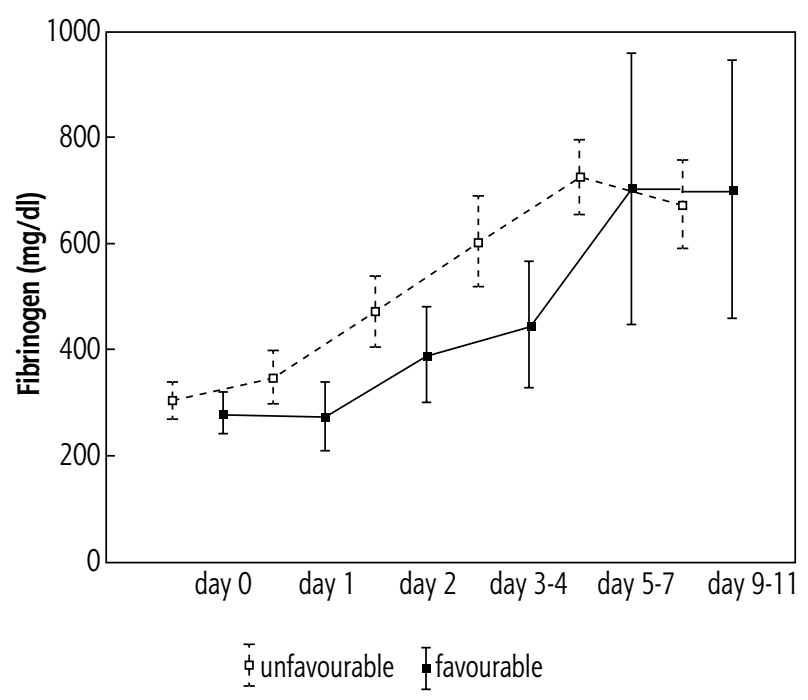

Fig. 1. Changes in plasma fibrinogen level in time in patients with favourable and unfavourable treatment outcome

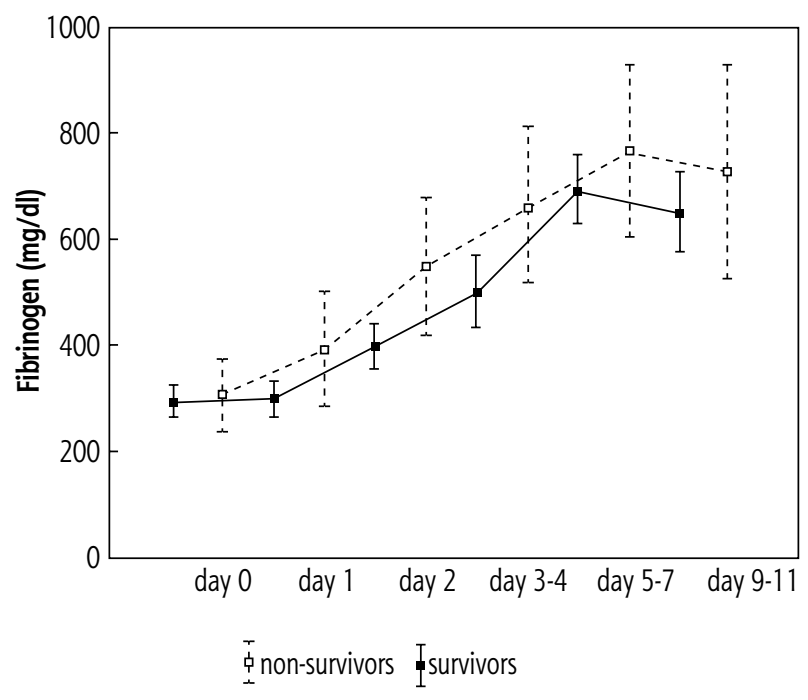

Fig. 2. Changes in plasma fibrinogen level in time in survivors and non-survivors of subarachnoid haemorrhage

Table 3. Comparison between survivors and non-survivors of subarachnoid haemorrhage

\begin{tabular}{|c|c|c|c|c|c|}
\hline \multirow[t]{2}{*}{ Variables } & \multicolumn{2}{|r|}{ Survivors } & \multicolumn{2}{|r|}{ Non-survivors } & \multirow[t]{2}{*}{$p$-value } \\
\hline & $n$ & mean $\pm S D /$ median $(Q 1 ; Q 3)$ & $n$ & mean $\pm \mathrm{SD} /$ median $(\mathrm{Q} 1 ; \mathrm{Q} 3)$ & \\
\hline Age & 67 & $54.5 \pm 14.0$ & 30 & $59.3 \pm 14.3$ & 0.0642 \\
\hline $\mathrm{HH}$ on admission & 67 & $3(2 ; 4)$ & 30 & $5(5 ; 5)$ & $<0.0001^{*}$ \\
\hline WFNS on admission & 67 & $4(1 ; 5)$ & 30 & $5(4 ; 5)$ & $0.0001^{*}$ \\
\hline GCS on admission & 67 & $12(6 ; 15)$ & 30 & $4(3 ; 6)$ & $<0.0001^{*}$ \\
\hline Fibrinogen $(\mathrm{mg} / \mathrm{dl})$, day 0 & 34 & $294.5 \pm 85.0$ & 12 & $307.6 \pm 108.1$ & 0.6718 \\
\hline Fibrinogen (mg/dl), day 1 & 26 & $301.1 \pm 84.9$ & 12 & $394.8 \pm 169.1$ & 0.0921 \\
\hline Fibrinogen (mg/dl), day 2 & 20 & $400.5 \pm 92.1$ & 9 & $551.6 \pm 168.7$ & $0.0302^{*}$ \\
\hline Fibrinogen (mg/dl), days 3-4 & 29 & $504.0 \pm 178.7$ & 18 & $668.6 \pm 300.5$ & $0.0459^{*}$ \\
\hline Fibrinogen (mg/dl), days 5-7 & 31 & $700.2 \pm 182.7$ & 15 & $771.5 \pm 296.1$ & 0.4025 \\
\hline Fibrinogen (mg/dl), days 9-11 & 31 & $656.5 \pm 207.9$ & 12 & $732.9 \pm 321.1$ & 0.3615 \\
\hline
\end{tabular}

Statistical significance for pairwise comparisons between the groups of death/survivor was tested by Student's t-test, Cochran-Cox correction or the Mann-Whitney test as appropriate. Values are presented as: 1) mean \pm standard deviation for numerical data, 2) median (lower quartile, upper quartile) for ordinal data. "significant p-value. Q - quartile; SD - standard deviation; HH - Hunt and Hess scale; WFNS - World Federation of Neurosurgical Societies scale; GCS - Glasgow Coma Scale

fibrinogen level on day $2(\mathrm{cc}=-0.476)$, independent of age $(\mathrm{cc}=-0.229)$. Univariate analysis of the unfavourable outcomes confirmed that fibrinogen levels failed to differentiate between the two groups (Table 5). However, univariate analysis for mortality indicated that the fibrinogen level on day $1(\mathrm{OR}=1.90[1.02 ; 3.57], p=0.0444)$, day $2(\mathrm{OR}=2.87[1.15 ; 7.15], p=0.0239)$ and day $3-4$ $(\mathrm{OR}=1.37[1.02 ; 1.85], p=0.0379)$ were predictors for mortality. Despite this, multivariate analysis adjusted for age and $\mathrm{HH}$ scores showed that the fibrinogen level was not an independent predictor (Table 6). We also analysed the relationship between fibrinogen level on day 2 post$\mathrm{SAH}$, clinical condition on admission and the extent of haemorrhage in imaging studies (Table 7). We found a statistically significant elevation of fibrinogen level on day 2 (correlating with treatment outcome) in patients with an intraventricular haematoma $(p<0.01)$. We also noted that fibrinogen level was elevated in patients with a GCS score less than $13(p=0.013)$.

\section{DISCUSSION}

Changes of coagulation and fibrinolytic mechanisms in relation to SAH have been analyzed since 1970 [29]. Elevated fibrinogen level is associated with the severity of the ischaemic event [30], and a sustained increase in 
the fibrinogen level during a stroke reduces the prospect of a favourable outcome [31]. Patients with DINDs have been reported to have higher levels of fibrinogen on days 3, 6 and 14 [32]. Our study demonstrated a significant difference in fibrinogen levels between survivors and non-survivors on days 1, 2 and 3-4. There was a constant increase in fibrinogen level on consecutive days follow-

Table 4. Correlation between patient age, clinical status on admission, fibrinogen level and outcome

\begin{tabular}{lccc}
\hline Variables & $n$ & Correlation coefficient & $p$-value \\
\hline Age & 97 & -0.229 & 0.0240 \\
\hline HH on admission & 97 & -0.669 & $<0.0001$ \\
\hline WFNS on admission & 97 & -0.630 & $<0.0001$ \\
\hline GCS score on admission & 97 & 0.679 & $<0.0001$ \\
\hline Fibrinogen day 0 & 46 & -0.123 & 0.4136 \\
\hline Fibrinogen day 1 & 38 & -0.309 & 0.0588 \\
\hline Fibrinogen day 2 & 29 & -0.476 & 0.0090 \\
\hline Fibrinogen days 3-4 & 47 & -0.358 & 0.0135 \\
\hline Fibrinogen days 5-7 & 46 & -0.100 & 0.5075 \\
\hline Fibrinogen days 9-11 & 43 & -0.052 & 0.7411 \\
\hline Outcome assessed using & & &
\end{tabular}

Outcome assessed using Glasgow Outcome Scale at 3 months. Statistical significance was tested by Spearman's rank correlation test. Correlation coefficient $>0.4$ or $<-0.4$ was considered significant and shown in bold. HH - Hunt and Hess scale; WFNS - World Federation of Neurosurgical Societies scale; GCS Glasgow Coma Scale ing SAH with a significant negative correlation between GOS and fibrinogen on day 2. Univariate analysis confirmed that the fibrinogen level on day 2 was a predictor for mortality; however, multivariate analysis showed it was not independent of the HH score. Patient's age and clinical status at admission were correlated with outcome. Increased fibrinogen levels at baseline and postSAH days 1 to 4 were observed but were not significantly correlated with outcome. Multivariate analysis adjusted for age and $\mathrm{HH}$ scores showed that the fibrinogen level was not an independent predictor. Fibrinogen levels were significantly elevated in patients with intraventricular haematoma. On day 2 fibrinogen level was also significantly elevated in patients with a GCS score less than 13 . It is therefore difficult to predict whether fibrinogen level changes represent activation of the coagulation system as the response to the severity of brain tissue damage. Coagulation and inflammation are intricately related processes. A combination of ischaemia and hypoxia precipitates platelet accumulation and fibrinogen deposition almost immediately [33]. Fibrinogen is an acute-phase coagulation factor produced by hepatocytes and is activated by thrombin to form fibrin monomers and polymers [34]. The early blood flow reduction is postulated to be due to microcirculatory constriction and microthrombosis. Platelet aggregates are found in the major cerebral arteries within two hours of experimental SAH [35]. The elevation of fibrinogen might represent microclot formation within $24 \mathrm{~h}$ after SAH [36]. This might be one reason for the beneficial effect of nimodipine [37], which may improve recovery from ischaemia by increasing fibrinolytic activity [38]. On the other hand, previous studies

Table 5. Univariate and multivariate logistic regression analysis for unfavourable outcome

\begin{tabular}{|c|c|c|c|c|}
\hline \multirow[t]{2}{*}{ Variables } & \multicolumn{2}{|c|}{ Univariate analysis } & \multicolumn{2}{|c|}{ Multivariate analysis ${ }^{*}$} \\
\hline & OR $(95 \% \mathrm{Cl})^{\dagger}$ & $p$-value & OR $(95 \% \mathrm{Cl})^{\dagger}$ & $p$-value \\
\hline Age & $1.04(1.00 ; 1.07)$ & 0.0262 & - & - \\
\hline HH on admission & $3.52(2.13 ; 5.81)$ & $<0.0001$ & - & - \\
\hline WFNS on admission & $2.73(1.86 ; 4.01)$ & $<0.0001$ & - & - \\
\hline GCS on admission & $0.71(0.61 ; 0.82)$ & $<0.0001$ & - & - \\
\hline Fibrinogen $(\mathrm{mg} / \mathrm{dl})$, day 0 & $1.36(0.67 ; 2.78)$ & 0.3917 & $1.18(0.34 ; 4.08)$ & 0.7949 \\
\hline Fibrinogen $(\mathrm{mg} / \mathrm{dl})$, day 1 & $1.99(0.81 ; 4.86)$ & 0.1325 & $2.63(0.58 ; 12.00)$ & 0.2105 \\
\hline Fibrinogen $(\mathrm{mg} / \mathrm{dl})$, day 2 & $1.72(0.82 ; 3.63)$ & 0.1517 & $1.46(0.45 ; 4.73)$ & 0.5292 \\
\hline Fibrinogen $(\mathrm{mg} / \mathrm{dl})$, days 3-4 & $1.48(0.97 ; 2.25)$ & 0.0681 & $1.36(0.78 ; 2.38)$ & 0.2798 \\
\hline Fibrinogen $(\mathrm{mg} / \mathrm{dl})$, days 5-7 & $1.05(0.71 ; 1.54)$ & 0.8170 & $1.07(0.66 ; 1.74)$ & 0.7921 \\
\hline Fibrinogen (mg/dl), days 9-11 & $0.95(0.67 ; 1.35)$ & 0.7795 & $1.01(0.67 ; 1.52)$ & 0.9541 \\
\hline
\end{tabular}

${ }^{*}$ Model adjusted for age and $\mathrm{HH}$ scale; ${ }^{+}$odds ratio corresponds to increase of $100 \mathrm{mg} / \mathrm{dl}$ in fibrinogen level and a unit increase in the rest of variables. Significant results are bolded. OR - odds ratio; $\mathrm{Cl}$ - confidence interval; HH - Hunt and Hess scale; WFNS - World Federation of Neurosurgical Societies scale; GCS - Glasgow Coma Scale 
Table 6. Univariate and multivariate logistic regression analysis for mortality

\begin{tabular}{|c|c|c|c|c|}
\hline \multirow[t]{2}{*}{ Variables } & \multicolumn{2}{|c|}{ Univariate analysis } & \multicolumn{2}{|c|}{ Multivariate analysis ${ }^{*}$} \\
\hline & OR $(95 \% \mathrm{Cl})^{\dagger}$ & $p$-value & OR $(95 \% \mathrm{Cl})^{\dagger}$ & $p$-value \\
\hline Age & $1.03(0.99 ; 1.06)$ & 0.1315 & - & - \\
\hline $\mathrm{HH}$ on admission & $3.10(1.71 ; 5.61)$ & 0.0002 & - & - \\
\hline WFNS on admission & $2.29(1.39 ; 3.78)$ & 0.0011 & - & - \\
\hline GCS on admission & $0.75(0.65 ; 0.87)$ & 0.0001 & - & - \\
\hline Fibrinogen $(\mathrm{mg} / \mathrm{dl})$, day 0 & $1.17(0.57 ; 2.42)$ & 0.6641 & $0.93(0.31 ; 2.77)$ & 0.8946 \\
\hline Fibrinogen (mg/dl), day 1 & $1.90(1.02 ; 3.57)$ & 0.0444 & $1.90(0.89 ; 4.07)$ & 0.0968 \\
\hline Fibrinogen $(\mathrm{mg} / \mathrm{dl})$, day 2 & $2.87(1.15 ; 7.15)$ & 0.0239 & $2.26(0.84 ; 6.06)$ & 0.1055 \\
\hline Fibrinogen (mg/dl), days 3-4 & $1.37(1.02 ; 1.85)$ & 0.0379 & $1.33(0.93 ; 1.92)$ & 0.1228 \\
\hline Fibrinogen (mg/dl), days 5-7 & $1.16(0.87 ; 1.53)$ & 0.3139 & $1.30(0.95 ; 1.78)$ & 0.1055 \\
\hline Fibrinogen (mg/dl), days 9-11 & $1.14(0.86 ; 1.50)$ & 0.3541 & $1.21(0.89 ; 1.64)$ & 0.2156 \\
\hline
\end{tabular}

${ }^{*}$ Model adjusted for $\mathrm{HH}$ scale; ${ }^{+}$odds ratio corresponds to increase of $100 \mathrm{mg} / \mathrm{dl}$ in fibrinogen level and a unit increase in the rest of variables. Significant results are bolded. OR - odds ratio; $\mathrm{Cl}$ - confidence interval; $\mathrm{HH}$ - Hunt and Hess scale; WFNS - World Federation of Neurosurgical Societies scale; GCS - Glasgow Coma Scale

Table 7. Relationship of fibrinogen level on post-subarachnoid haemorrhage day 2 to clinical condition on admission and extent of haemorrhage on imaging studies

\begin{tabular}{|c|c|c|c|c|c|}
\hline \multirow[t]{2}{*}{ Variables } & \multicolumn{2}{|c|}{ Yes } & \multicolumn{2}{|c|}{ No } & \multirow[t]{2}{*}{$p$-value } \\
\hline & $n$ & mean $\pm S D$ & $n$ & mean $\pm S D$ & \\
\hline Intraventricular haematoma & 21 & $492.4 \pm 133.2$ & 8 & $329.1 \pm 55.3$ & $<0.01^{*}$ \\
\hline Intracerebral haematoma & 15 & $458.7 \pm 119.8$ & 14 & $435.2 \pm 158.3$ & 0.655 \\
\hline Intraventricular and intracerebral haematoma & 13 & $483.2 \pm 105.7$ & 16 & $418.1 \pm 156.2$ & 0.100 \\
\hline Good clinical condition on admission (GCS 15-13) & 9 & $355.8 \pm 87.6$ & 20 & $488.6 \pm 137.6$ & $0.013^{*}$ \\
\hline
\end{tabular}

"Significant results; GCS - Glasgow Coma Scale; SD - standard deviation

have also shown that nimodipine is an effective cerebral vasodilator, making it useful in the treatment of cerebral vasospasm [39]. Fibrinogen and its degradation products have a prominent role in the regulation of the inflammatory response in several target tissues [40]. Pathological conditions such as injury, or disease associated with vascular disruption, infection or inflammation, increase the blood concentration of fibrinogen several fold [40]. Fibrinogen has been shown to activate the proinflammatory NF- $\kappa \beta$ pathway, which results in the local production of inflammatory cytokines TNF- $\alpha$ and IL-1 $\beta$ [41-43]. Fibrinogen signals either directly or indirectly through a number of other receptors, adhesion molecules and cell-surface proteins that are involved in the inflammatory processes. For example, the toll-like receptor 4 (TLR-4) related to SAH [44] has been implicated in the induction of macrophage activation and the release of several chemokines and cytokines $[45,46]$. Some authors have reported increased levels of TAT, thrombin/antithrombin complex (a marker for activation of the coagulation cascade), and D-dimer (marker for plasmatic fibrinolysis) and their association with poor outcome. Additionally, the correlation between fibrinogen and outcome varied and therefore was inconclusive [47-49].

\section{CONCLUSIONS}

This study was designed to investigate the association between plasma fibrinogen levels and patient outcome following SAH. There were three limitations: firstly, data were collected prospectively and analysed retrospectively; secondly, the number of readings available was limited; thirdly, plasma levels may not precisely reflect local changes at the site of SAH. For the patient population in this study, we found a significant negative correlation between GOS and plasma fibrinogen level on day two after SAH. We also found that elevation of fibrinogen levels on day 2 and days 3-4 after SAH was associated with increased mortality. Larger prospective studies will be required to reassess fibrinogen levels following SAH and establish whether they have a role in the development of DINDs. Fibrinogen level on the second day after SAH was significantly elevated in patients with intraventricular haematoma. This significance was not present 
in patients with intracerebral haematoma. Patients with a poor clinical condition on admission also had elevated fibrinogen levels on day two.

\section{The authors declare no conflict of interest.}

\section{References}

1. Ikawa F, Abiko M, Ishii D, Ohshita J, Matsushige T, Okazaki T, Sakamoto S, Hida E, Kobayashi S, Kurisu K, et al. Analysis of outcome at discharge after aneurysmal subarachnoid hemorrhage in Japan according to the Japanese stroke databank. Neurosurg Rev 2018; 41: 567-574.

2. Connolly ES, Rabinstein AA, Carhuapoma JR, Derdeyn CP, Dion J, Higashida RT, Hoh BL, Kirkness CJ, Naidech AM, Ogilvy CS, Patel AB, Thompson BG, Vespa P; American Heart Association Stroke Council; Council on Cardiovascular Radiology and Intervention; Council on Cardiovascular Nursing; Council on Cardiovascular Surgery and Anesthesia; Council on Clinical Cardiology. Guidelines for the management of aneurysmal subarachnoid hemorrhage: a guideline for healthcare professionals from the American Heart Association/American Stroke Association. Stroke 2012; 43: 1711-1737.

3. Bederson JB, Connolly ES, Batjer HH, Dacey RG, Dion JE, Diringer MN, Duldner JE Jr, Harbaugh RE, Patel AB, Rosenwasser RH; American Heart Association. Guidelines for the management of aneurysmal subarachnoid hemorrhage: a statement for healthcare professionals from a special writing group of the Stroke Council, American Heart Association. Stroke 2009; 40: 994-1025.

4. Turner CL, Budohoski K, Smith C, Hutchinson PJ, Kirkpatrick PJ. Elevated baseline C-reactive protein as a predictor of outcome after aneurysmal subarachnoid hemorrhage: Data from the Simvastatin in Aneurysmal Subarachnoid Hemorrhage (STASH) trial. Neurosurgery 2015; 77: 786-792.

5. Hütter BO, Kreitschmann-Andermahr I, Mayfrank L, Rohde V, Spetzger U, Gilsbach JM. Functional outcome after aneurysmal subarachnoid hemorrhage. Acta Neurochir Suppl 1999; 72: 157-174.

6. Hackett ML, Anderson CS, Group for the ACR on SHS (ACROSS). Health outcomes 1 year after subarachnoid hemorrhage: An international population-based study. The Australian Cooperative Research on Subarachnoid Hemorrhage Study Group. Neurology [Internet]. Lippincott Williams \& Wilkins 2000; 55: 658-662.

7. Jennett B, Bond M. Assessment of outcome after severe brain damage. Lancet 1975; 1: 480-484.

8. Hunt WE, Hess RM. Surgical risk as related to time of intervention in the repair of intracranial aneurysms. J Neurosurg 1968; 28: $14-20$.

9. Ogungbo B. The World Federation of Neurological Surgeons scale for subarachnoid hemorrhage. Surg Neurol 2003; 59: 236237; discussion 237-238.

10. Fisher CM, Kistler JP, Davis JM. Relation of cerebral vasospasm to subarachnoid hemorrhage visualized by computerized tomographic scanning. Neurosurgery 1980; 6: 1-9.

11. Rosengart AJ, Schultheiss KE, Tolentino J, Macdonald RL. Prognostic factors for outcome in patients with aneurysmal subarachnoid hemorrhage. Stroke 2007; 38: 2315-2321.
12. Rabb CH, Tang G, Chin LS, Giannotta SL. A statistical analysis of factors related to symptomatic cerebral vasospasm. Acta Neurochir (Wien) 1994; 127: 27-31.

13. Shen J, Pan J-W, Fan Z-X, Xiong X-X, Zhan R-Y. Dissociation of vasospasm-related morbidity and outcomes in patients with aneurysmal subarachnoid hemorrhage treated with clazosentan: a meta-analysis of randomized controlled trials. J Neurosurg 2013; 119: 180-189.

14. Caner B, Hou J, Altay O, Fuj M, Zhang JH. Transition of research focus from vasospasm to early brain injury after subarachnoid hemorrhage. J Neurochem 2012; 123 (Suppl 2): 12-21.

15. MacDonald RL, Kassell NF, Mayer S, Ruefenacht D, Schmiedek P, Weidauer S, Frey A, Roux S, Pasqualin A; CONSCIOUS-1 Investigators. Clazosentan to overcome neurological ischemia and infarction occurring after subarachnoid hemorrhage (CONSCIOUS-1): Randomized, double-blind, placebo-controlled phase 2 dose-finding trial. Stroke 2008; 39: 3015-3021.

16. Zuccarello M. Cerebral Vasospasm: Neurovascular Events After Subarachnoid Hemorrhage. Acta Neurochir Suppl 2013; 115: 1-5.

17. Vergouwen MDI, Vermeulen M, van Gijn J, Rinkel GJE, Wijdicks EF, Muizelaar JP, Mendelow AD, Juvela S, Yonas H, Terbrugge KG, Macdonald RL, Diringer MN, Broderick JP, Dreier JP, Roos YB. Definition of delayed cerebral ischemia after aneurysmal subarachnoid hemorrhage as an outcome event in clinical trials and observational studies: proposal of a multidisciplinary research group. Stroke 2010; 41: 2391-2395.

18. Cahill J, Zhang JH. Subarachnoid hemorrhage: is it time for a new direction? Stroke 2009; 40 (3 Suppl): S86-87.

19. Sehba FA, Hou J, Pluta RM, Zhang JH. The importance of early brain injury after subarachnoid hemorrhage. Prog Neurobiol 2012; 97: 14-37.

20. Sabri M, Lass E, Macdonald RL. Early Brain Injury: A Common Mechanism in Subarachnoid Hemorrhage and Global Cerebral Ischemia. Stroke Res Treat 2013; 2013: 394036.

21. Carr KR, Zuckerman SL, Mocco J. Inflammation, cerebral vasospasm, and evolving theories of delayed cerebral ischemia. Neurol Res Int 2013; 2013: 506584.

22. Dumont AS, Dumont RJ, Chow MM, Lin C-L, Calisaneller T, Ley KF, Kassell NF, Lee KS. Cerebral vasospasm after subarachnoid hemorrhage: putative role of inflammation. Neurosurgery 2003; 53: 123-133; discussion 133-135.

23. Chaichana KL, Pradilla G, Huang J, Tamargo RJ. Role of inflammation (leukocyte-endothelial cell interactions) in vasospasm after subarachnoid hemorrhage. World Neurosurg 2010; 73 : $22-41$.

24. Al-Mufti F, Amuluru K, Smith B, Damodara N, El-Ghanem M, Singh IP, Dangayach N, Gandhi CD. Emerging Markers of Early Brain Injury and Delayed Cerebral Ischemia in Aneurysmal Subarachnoid Hemorrhage. World Neurosurg 2017; 107: 148159.

25. Muroi C, Hugelshofer M, Seule M, Tastan I, Fujioka M, Mishima K, Keller E. Correlation among systemic inflammatory parameter, occurrence of delayed neurological deficits, and outcome after aneurysmal subarachnoid hemorrhage. Neurosurgery 2013; 72: 367-375.

26. Hunt WE, Hess RM. Surgical Risk as Related to Time of Intervention in the Repair of Intracranial Aneurysms. J Neurosurg 1968; 28: $14-20$

27. Drake C. Report of World Federation of Neurological Surgeons Committee on a Universal Subarachnoid Hemorrhage Grading Scale. J Neurosurg 1988; 68: 985-986. 
28. Jennett B, Bond M. Assessment of outcome after severe brain damage. A Practical Scale. Lancet 1975; 305: 480-484.

29. Ettinger MG. Coagulation abnormalities in subarachnoid hemorrhage. Stroke 1970; 1: 139-142.

30. Del Zoppo GJ, Levy DE, Wasiewski WW, Pancioli AM, Demchuk AM, Trammel J, Demaerschalk BM, Kaste M, Albers GW, Ringelsteinet EB. Hyperfibrinogenemia and Functional Outcome From Acute Ischemic Stroke. Stroke 2009; 40: 1687-1691.

31. Swarowska M, Janowska A, Polczak A, Klimkowicz-Mrowiec A, Pera J, Slowik A, Dziedzic T. The Sustained Increase of Plasma Fibrinogen During Ischemic Stroke Predicts Worse Outcome Independently of Baseline Fibrinogen Level. Inflammation 2014; 37: 1142-1147.

32. Fujii Y, Takeuchi S, Sasaki O, Minakawa T, Koike T, Tanaka R. Serial changes of hemostasis in aneurysmal subarachnoid hemorrhage with special reference to delayed ischemic neurological deficits. J Neurosurg 1997; 86: 594-602.

33. Adhami F, Liao G, Morozov YM, Schloemer A, Schmithorst VJ, Lorenz JN, Dunn RS, Vorhees CV, Wills-Karp M, Degen JL, Davis RJ, Mizushima N, Rakic P, Dardzinski BJ, Holland SK, Sharp FR, Kuan CY. Cerebral ischemia-hypoxia induces intravascular coagulation and autophagy. Am J Pathol 2006; 169: 566-583.

34. Tennent GA, Brennan SO, Stangou AJ, O’Grady J, Hawkins PN, Pepys MB. Human plasma fibrinogen is synthesized in the liver. Blood 2007; 109: 1971-1975.

35. Sehba FA, Mostafa G, Friedrich V, Bederson JB. Acute microvascular platelet aggregation after subarachnoid hemorrhage. J Neurosurg 2005; 102: 1094-1100.

36. Andereggen L, Neuschmelting V, von Gunten M, Widmer HR, Fandino J, Marbacher S. The role of microclot formation in an acute subarachnoid hemorrhage model in the rabbit. Biomed Res Int 2014; 2014: 161702.

37. Pickard JD, Murray GD, Illingworth R, Shaw MD, Teasdale GM, Foy PM, Humphrey PR, Lang DA, Nelson R, Richards P. Effect of oral nimodipine on cerebral infarction and outcome after subarachnoid hemorrhage: British aneurysm nimodipine trial. BMJ 1989; 298: 636-642.

38. Roos YB, Levi M, Carroll TA, Beenen LFM, Vermeulen M. Nimodipine Increases Fibrinolytic Activity in Patients With Aneurysmal Subarachnoid Hemorrhage Subjects and Methods. Stroke 2001; 32: 1860-1862.

39. Biondi A, Ricciardi GK, Puybasset L, Abdennour L, Longo M, Chiras J, Van Effenterre R. Intra-arterial nimodipine for the treatment of symptomatic cerebral vasospasm after aneurysmal subarachnoid hemorrhage: preliminary results. AJNR Am J Neuroradiol 2004; 25: 1067-1076.

40. Adams R, Schachtrup C, Davalos D, Tsigelny I, Akassoglou K. Fibrinogen Signal Transduction as a Mediator and Therapeutic Target in Inflammation: Lessons from Multiple Sclerosis. Curr Med Chem 2007; 14: 2925-2936.

41. Fan ST, Edgington TS. Integrin regulation of leukocyte inflammatory functions. CD11b/CD18 enhancement of the tumor necrosis factor-alpha responses of monocytes. J Immunol 1993; 150: 2972-2980.

42. Perez RL, Roman J. Fibrin enhances the expression of IL- 1 beta by human peripheral blood mononuclear cells. Implications in pulmonary inflammation. J Immunol 1995; 154: 1879-1887.
43. Perez RL, Ritzenthaler JD, Roman J. Transcriptional regulation of the interleukin-1beta promoter via fibrinogen engagement of the CD18 integrin receptor. Am J Respir Cell Mol Biol 1999; 20: 1059-1066.

44. Sokół B, Wąsik N, Jankowski R, Hołysz M, Więckowska B, Jagodziński P. Soluble Toll-Like Receptors 2 and 4 in Cerebrospinal Fluid of Patients with Acute Hydrocephalus following Aneurysmal Subarachnoid Haemorrhage. PLoS One 2016; 11: e0156171.

45. Smiley ST, King JA, Hancock WW. Fibrinogen stimulates macrophage chemokine secretion through toll-like receptor 4 . J Immunol 2001; 167: 2887-2894.

46. Davalos D, Akassoglou K. Fibrinogen as a key regulator of inflammation in disease. Semin Immunopathol 2012; 34: 43-62.

47. Nina P, Schisano G, Chiappetta F, Luisa Papa M, Maddaloni E, Brunori A, Capasso F, Corpetti MG, Demurtas F. A study of blood coagulation and fibrinolytic system in spontaneous subarachnoid hemorrhage: Correlation with hunt-hess grade and outcome. Surg Neurol 2001; 55: 197-203.

48. Frontera JA, Aledort L, Gordon E, Egorova N, Moyle H, Patel A, Bederson JB, Sehba F. Early platelet activation, inflammation and acute brain injury after a subarachnoid hemorrhage: A pilot study. J Thromb Haemost 2012; 10: 711-713.

49. Juvela S, Siironen J. D-dimer as an independent predictor for poor outcome after aneurysmal subarachnoid hemorrhage. Stroke 2006; 37: 1451-1456. 